\title{
Outdoor work as a risk factor for high-grade cutaneous squamous cell carcinoma of the head and neck
}

\author{
Mateusz Szewczyk ${ }^{1}$, Jakub Pazdrowski ${ }^{1}$, Paweł Golusiński ${ }^{1,2}$, Aleksandra Dańczak-Pazdrowska ${ }^{3}$, Mariola Pawlaczyk ${ }^{4}$, \\ Jacek Sygut ${ }^{5}$, Andrzej Marszałek ${ }^{5}$, Wojciech Golusiński ${ }^{1}$
}

${ }^{1}$ Department of Head and Neck Surgery, Poznan University of Medical Sciences, The Greater Poland Cancer Centre, Poznan, Poland ${ }^{2}$ Department of Biology and Environmental Studies, Poznan University of Medical Sciences, Poznan, Poland ${ }^{3}$ Department of Dermatology, Poznan University of Medical Sciences, Poznan, Poland

${ }^{4}$ Department of Gerontology and Geriatric Medicine, Poznan University of Medical Sciences, Poznan, Poland

${ }^{5}$ Department of Cancer Pathology and Prophylaxis, Poznan University of Medical Sciences, The Greater Poland Cancer Centre, Poznan, Poland

Adv Dermatol Allergol 2018; XXXV (4): 408-412

DOI: https://doi.org/10.5114/ada.2018.75841

\begin{abstract}
Introduction: While it is clear that individuals with outdoor occupations are at a significantly greater risk of developing cutaneous squamous cell carcinoma (CSCC), no previous studies have investigated the potential association between the tumour grade and occupation in this patient population.

Aim: To assess occupation as a risk factor for the development of high-grade cSCC. Secondarily, to determine the association between the tumour grade and other clinical characteristics.

Material and methods: Retrospective analysis of 256 patients treated for head and neck cSCC at our institution in 2007-2016. The following patient characteristics and variables were assessed: age; sex; tumour location and grade; profession; and education level. A univariate analysis was performed to assess the association between each study variable and grade 3 tumour differentiation.

Results: The following variables were significantly associated $(p<0.05)$ with grade 3 (G3) cSCC tumours: outdoor work vs. indoor work; primary school vs. high school education; and age. Additionally, patients with low-grade (G1) tumours were significantly younger (mean age: 72 ) than patients with high-grade (G3) tumours (mean age: 79$)$ $(p=0.046)$.

Conclusions: To our knowledge, this is the first study to assess the variables associated with the tumour grade among outdoor workers. These findings suggest that outdoor workers who develop CSCC are at a greater risk of developing more aggressive cancers. These findings provide additional support for classifying CSCC as an occupational disease. Early education about the dangers of sun exposure during the first years of school is essential to minimize the risks of developing high-grade skin cancer.
\end{abstract}

Key words: skin cancer, head neck, occupational disease, grading.

\section{Introduction}

Cutaneous squamous cell carcinoma (cSCC) is, after basal cell carcinoma, the second most common cancer in the world [1]. The overall incidence is $16 / 100,000$ in Europe and 160/100,000 and 356/100,000 in the United States and Australia, respectively [2, 3]. Prognosis is generally good, although approximately $10 \%$ of cases will develop regional metastases and thus significantly higher mortality rates $[4,5]$. The most important etiological factor is total lifetime exposure to ultraviolet A (UVA) and B radiation (UVB) $[6,7]$. Solar UV radiation causes genetic damage in skin keratinocytes, thus leading to neoplastic changes in the tissue [8].

Although the relation between UV radiation and cSCC has been well established [9-11], cSCC is not currently considered an occupational disease. An occupational disease is defined as an illness caused by the action of harmful factors in the work environment or in the way the employee works. Although this definition would appear to include skin diseases among outdoor workers, these diseases are not included in the group of occupational diseases in most countries. A notable exception to this is Germany, where certain skin can-

Address for correspondence: Mateusz Szewczyk MD, Department of Head and Neck Surgery, Poznan University of Medical Sciences, The Greater Poland Cancer Centre, 15 Garbary St, 61-866 Poznan, Poland, phone: +48 609540 393, e-mail: mateuszszewczyk@yahoo.pl Received: 6.06.2017, accepted: 12.07.2017. 
cers - that is, those caused by exposure to soot, paraffin sludge, tar, anthracene, pitch, or similar substances - are classified as occupational diseases. UV radiation is conspicuously absent on this list of causes [12]. Nevertheless, it is clear that outdoor workers are more likely to receive a higher cumulative dose of solar radiation. The consequence of this greater exposure is that such patients have a greater probability than non-UVB-exposed workers of developing higher grade (i.e. poorlydifferentiated) tumours with a worse prognosis [13-15]. Indeed, one author found that the metastasis rate in patients with poorly-differentiated tumours was three times greater than that of patients with moderately- or well-differentiated tumours [16]. While it is clear that individuals with outdoor occupations are at a significantly greater risk of developing CSCC, to our knowledge, no previous studies have investigated the potential association between the tumour grade and occupation in this patient population.

\section{Aim}

Given this context, we hypothesized that outdoor workers would be more likely to develop cSCC than indoor workers, and that the tumour grade in this subpopulation would be higher. The primary aim of this study was to determine the potential association between occupation (outdoor vs. indoor work) and the tumour grade. A secondary aim was to assess the potential influence of other patient characteristics on the tumour grade.

\section{Material and methods}

This was a retrospective study of patients who underwent surgical treatment for cSCC between 2007 and 2016 at our institution. Inclusion criteria were: a) diagnosis of cSCC (any grade or type) and b) surgery as the primary oncological treatment. A total of 294 patients met the inclusion criteria. Of these, 38 were excluded from the final analysis for the following reasons: 16 were lost to follow-up, 18 changed their jobs during the study evaluation period (and were thus re-classified to another occupational group), and another 4 could not be reached by telephone query. Therefore, the final sample consisted of 256 patients.

The following were obtained from patient medical records: sex; age at diagnosis; tumour location (forehead, nose, eye, cheek, scalp, ear, lip); tumour grade (1-3); and educational level: primary school (age: 7-15), secondary school (age: 15-19), or high school graduate (age: 19+). The patient's occupation was ascertained by telephone query and classified as one of the following: 1) outdoor worker (> 4 h/day of outdoor work); 2) mixed worker (between 2-4 h/day of outdoor work); or 3) indoor worker ( $<2 \mathrm{~h}$ /day of outdoor work).

\section{Statistical analysis}

A univariate analysis was performed for all study variables. The main analysis was performed to determine the association between the patient profession and degree of tumour differentiation. Similarly, a univariate analysis was performed for education and age to check for possible associations with tumour differentiation.

The statistical analysis was performed using Statistica statistical software (StatSoft). The results were considered significant at $p<0.05$. Comparisons were made using the Kruskal-Wallis test, Dunn's multiple comparisons test, the Mann-Whitney $U$ test, and a logistic regression model. Odds ratios (OR) with 95\% confidence intervals (CI) were calculated using Fisher's exact test with De Wolf's approximation.

Due to the retrospective nature of the study, the approval from the Research Ethics board was not obligated. Each patient on admission to the Department signed written consent to participate in the study.

\section{Results}

The sample of 256 patients consisted of 188 (73\%) males and 68 (27\%) females. The median age was 75 years (range: $28-97)$. The most common location was the lip (92 patients; 36\%), followed by the ear (65 patients; $25 \%$ ), and nose (37 patients; 14\%) (Table 1). The most common tumour grade was grade 2 (G2) (149 patients; 58\%), followed by G1 (80 patients; 32\%), and G3 (27 patients; 10\%). One hundred and eleven patients were classified as outdoor workers (43\%), 82 (32\%) as mixed, and 63 (25\%) as indoor workers (Table 2). Most patients had only a primary school educational level (189 patients; 74\%), followed by secondary school (46 patients; 18\%) and high school graduates (21 patients; 8\%) (Table 3).

Outdoor workers were significantly more likely to have a G3 tumour than a G1 tumour ( $p=0.0206$; $\mathrm{OR}=41.9 ; 95 \% \mathrm{Cl}: 2.37-748)$. By contrast, there were no G3 tumours within the indoor workers subset (Table 2). Due to vast confidence intervals we have combined $G 2$

Table 1. Tumour distribution according to the location and grade

\begin{tabular}{lccc}
\hline Location & $\begin{array}{c}\text { Grade } 1 \\
N=80 \\
n(\%)\end{array}$ & $\begin{array}{c}\text { Grade 2 } \\
N=149 \\
n(\%)\end{array}$ & $\begin{array}{c}\text { Grade 3 } \\
N=27 \\
n(\%)\end{array}$ \\
\hline Forehead & $0(0)$ & $8(5.4)$ & $0(0)$ \\
\hline Nose & $11(13.8)$ & $24(16.1)$ & $2(7.4)$ \\
\hline Orbital & $2(2.5)$ & $2(1.3)$ & $1(3.7)$ \\
\hline Cheek & $10(12.5)$ & $23(15.4)$ & $9(33.3)$ \\
\hline Scalp & $3(3.8)$ & $3(2.0)$ & $1(3.7)$ \\
\hline Ear & $20(25.0)$ & $36(24.2)$ & $9(33.3)$ \\
\hline Lip & $34(42.5)$ & $53(35.6)$ & $5(18.5)$ \\
\hline
\end{tabular}


Table 2. Tumour differentiation according to profession

\begin{tabular}{|c|c|c|c|c|c|c|c|c|c|}
\hline Profession & $\begin{array}{c}\text { Grading I } \\
N=80\end{array}$ & $\begin{array}{c}\text { Grading II } \\
N=149\end{array}$ & $\begin{array}{c}\text { Grading III } \\
N=27\end{array}$ & $\begin{array}{c}\text { Statistical } \\
\text { significance } \\
\text { I vs. II }\end{array}$ & $\begin{array}{l}\text { Statistical } \\
\text { significance } \\
\text { I vs. III }\end{array}$ & $\begin{array}{l}\text { Statistical } \\
\text { significance } \\
\text { II vs. III }\end{array}$ & $\begin{array}{c}\text { OR } \\
95 \% \mathrm{Cl} \\
\text { I vs. II }\end{array}$ & $\begin{array}{c}\text { OR } \\
95 \% \mathrm{Cl} \\
\text { I vs. III }\end{array}$ & $\begin{array}{c}\text { OR } \\
95 \% \text { CI } \\
\text { II vs. III }\end{array}$ \\
\hline Outdoor & 22 & 75 & 14 & 0.0009 & 0.0206 & 0.9611 & $\begin{array}{c}3.52 \\
1.77-6.98\end{array}$ & $\begin{array}{c}41.9 \\
2.37-748\end{array}$ & $\begin{array}{c}12.1 \\
0.7-209\end{array}$ \\
\hline Mixed & 26 & 43 & 13 & 0.5671 & 0.1440 & 0.0477 & $\begin{array}{c}1.71 \\
0.85-3.4\end{array}$ & $\begin{array}{c}33.1 \\
1.88-583\end{array}$ & $\begin{array}{c}19.6 \\
1.12-341\end{array}$ \\
\hline Indoor & 32 & 31 & 0 & 0.0019 & 0.0001 & 0.0090 & & & \\
\hline
\end{tabular}

Table 3. Tumour differentiation according to education

\begin{tabular}{|c|c|c|c|c|c|c|c|c|c|}
\hline Education & $\begin{array}{c}\text { Grading I } \\
N=80\end{array}$ & $\begin{array}{c}\text { Grading II } \\
N=149\end{array}$ & $\begin{array}{c}\text { Grading III } \\
\quad N=27\end{array}$ & $\begin{array}{l}\text { Statistical } \\
\text { significance } \\
\text { I vs. II }\end{array}$ & $\begin{array}{c}\text { Statistical } \\
\text { significance } \\
\text { I vs. III }\end{array}$ & $\begin{array}{l}\text { Statistical } \\
\text { significance } \\
\text { II vs. III }\end{array}$ & $\begin{array}{c}\text { OR } \\
95 \% \mathrm{Cl} \\
\text { I vs. II }\end{array}$ & $\begin{array}{c}\text { OR } \\
95 \% \mathrm{Cl} \\
\text { I vs. III }\end{array}$ & $\begin{array}{c}\text { OR } \\
95 \% \mathrm{Cl} \\
\text { II vs. III }\end{array}$ \\
\hline Primary & 47 & 119 & 23 & 0.0006 & 0.0125 & 0.5193 & $\begin{array}{c}3.37 \\
1.33-8.5\end{array}$ & $\begin{array}{c}12.37 \\
0.7-218\end{array}$ & $\begin{array}{c}3.74 \\
0.21-66.4\end{array}$ \\
\hline Secondary & 21 & 21 & 4 & 0.0234 & 0.2245 & 0.9214 & $\begin{array}{c}1.33 \\
0.46-3.83\end{array}$ & $\begin{array}{c}5.23 \\
0.25-105\end{array}$ & $\begin{array}{c}3.97 \\
0.19-81.5\end{array}$ \\
\hline High & 12 & 9 & 0 & 0.0251 & 0.0327 & 0.1899 & & & \\
\hline
\end{tabular}

Table 4. Tumour differentiation according to age (mean \pm SD)

\begin{tabular}{lccccccc}
\hline $\begin{array}{l}\text { Grading I } \\
N=80\end{array}$ & $\begin{array}{c}\text { Grading II } \\
N=149\end{array}$ & $\begin{array}{c}\text { Grading III } \\
N=27\end{array}$ & $\begin{array}{c}\text { Statistical } \\
\text { significance } \\
\text { I vs. II }\end{array}$ & $\begin{array}{c}\text { Statistical } \\
\text { significance } \\
\text { I vs. III }\end{array}$ & $\begin{array}{c}\text { Statistical } \\
\text { significance } \\
\text { II vs. III }\end{array}$ & $\begin{array}{c}\text { OR } \\
95 \% \mathrm{Cl}\end{array}$ & $\begin{array}{c}\text { OR } \\
\text { I vs. II }\end{array}$ \\
\hline $72 \pm 14.2$ & $76 \pm 11.5$ & $79 \pm 8.8$ & 0.1043 & 0.0460 & 0.7131 & $\begin{array}{c}\text { OR } \\
\text { I vs. III } \\
\text { II vs. III }\end{array}$ \\
\hline
\end{tabular}

and G3 subgroups. In this comparison patients working outdoors had a 4 times greater risk of developing $\mathrm{G} 2$ or G3 tumours than those working indoors $(p<0.0001$; $\mathrm{OR}=4.18 ; 95 \% \mathrm{Cl}: 2.12-8.24)$. Patients with primary education were over 3 times more likely to have a G2 cancer versus high school education ( $p=0.0006$; OR $=8.5$; 95\% Cl: 1.33-8.5) (Table 3). In combined groups patients with primary education had a 4 times greater chance of developing $\mathrm{G} 2$ or $\mathrm{G} 3$ tumours in comparison with high school graduates $(p=0.0032$; OR $=4.028 ; 95 \% \mathrm{Cl}: 1.59$ 10.16).

Mean patient age by the tumour grade (G1, G2, G3) was 72, 76, and 79 years, respectively (Table 4). The age was significantly associated with a higher likelihood of developing a G3 tumour, with the risk increasing by 1.06 per year starting at age 72 when comparing the G1 group to the $\mathrm{G} 3$ group ( $p=0.046$; OR $=1.06 ; 95 \% \mathrm{Cl}$ : 1.01-1.10) (Table 4).

There was no correlation between the patient sex and tumour grade.

Multivariate analysis was not possible due to the limited number of subjects with G1 and G3 tumours.

\section{Discussion}

In this study, we assessed the association between the occupation type (indoor, outdoor, or mixed) and tu- mour grade in patients with cSCC. The main findings were that patients who worked outdoors had a significantly greater risk (42 times) of developing a high grade (G3) tumour compared to those who worked indoors. In addition, we also found that a low educational level (primary school education only) was significantly associated with G3 cancers. Age was also correlated with tumour differentiation, with G3 tumours significantly more common in older patients. To our knowledge, this is the first study to evaluate the association between the tumour grade and CSCC among outdoor workers.

Most patients in this sample were older males (median age: 74), a finding that is consistent with previous reports showing that males are more likely to develop CSCC, in part because of their greater exposure to solar UV radiation through both occupation and outdoor hobbies [17]. Indeed, over half of the sample worked outdoors and of these, the large majority (99 patients; $89 \%)$ were males. The most common tumour locations were the lip, ear and nasal regions, all of which are areas that receive significant sun exposure, as noted by other authors [18, 19].

\section{Work environment conditions}

The main findings in this study were with regards to the association between the work location (out- 
door, mixed, or indoor) and tumour grade. Patients who worked outdoors were significantly more likely (> 40 times) to present a high grade tumour than patients who worked indoors. These findings were not entirely unexpected - indeed, our working hypothesis was that outdoor workers would have higher-grade tumours given that previous studies have estimated that outdoor workers receive UV doses that are 2 to 9 times higher than those received by indoor workers [20]. This differential exposure is crucial for the development of cSCC because it is believed that cSCC tumour cells develop from multiple genetic hits, mostly in the p53-tumour suppressor gene. Interestingly, a normal p53 gene is actually upregulated by sunlight exposure and acts as a tumour suppressor by increasing DNA repair, arresting the cell cycle, and inducing apoptosis of damaged keratinocytes; however, excessive UV exposure can cause mutations in this gene, thus allowing cells to become resistant to apoptosis. In a mouse model, Brash [13] found that when UVB exposure was halted, clone growth also ceased. However, the same author found that frequent UV radiation acts as a selection pressure by killing apoptosisnormal cells and favouring mutated cells, which eventually increase in numbers and expand. This mechanism could partially explain our results as outdoor workers presumably received continuous exposure [13, 20, 21]. Another study supporting our results was conducted on organotypic cultures with normal healthy keratinocytes and premalignant cells. The normal ratio of healthy to premalignant cells was $4: 1$, leading to elimination of the diseased cells. However, when the ratio was equal $(1: 1)$, the premalignant cells survived, proliferated and became invasive. Even a minimal erythemal UVB dose allowed the diseased cells to form clones and overwhelm normal keratinocytes [22].

\section{Education}

Another novel finding of our study is the association between education and CSCC tumour grade. We found that patients with a low educational level (primary school only) were more likely to present a G3 tumour compared to patients with higher levels of education (secondary education and high school graduates). The logical explanation for these findings is that, presumably, individuals with lower educational levels are more likely to work outdoors and, additionally, may be less aware of the risks of sun exposure. Reeder et al. noted that postal workers (whose educational level was higher than the comparison groups) had better knowledge of how to protect themselves from UV exposure [23]. Nahar et al. in his research discovered that only $35 \%$ of state park workers believed that their risk of developing skin cancer is higher than average [24]. Similarly, Buster et al. found that patients with lower educational levels were less worried about developing skin cancer, had less knowledge of methods of prevention, and "those without a college degree more often agreed that there are too many SC prevention recommendations to know what one should do" [25].

\section{Age}

Patients with G1 tumours were younger (mean age; 72), on average, than those with $\mathrm{G} 3$ tumours (mean: 79 years). In other words, G3 cancers were more common among the older patients in our cohort, and we found that the risk of developing a high grade, poorlydifferentiated tumour increased by 1.06 per year. Several authors have found that age is the strongest risk factor for developing cancer, although other authors indicate that the interaction between cancer and aging is complex, but that the increased risk of cancer development can be explained by accumulation of genomic mutations throughout life [26, 27]. Nevertheless, we were unable to find any other studies (apart from ours) reporting a direct relationship between aging and an increased risk of developing poorly-differentiated cancers.

Overall, the data in this retrospective study strongly suggest that outdoor work, low educational level, and age are factors that substantially increase the risk of developing a high-grade cSCC tumour. It is important to stress that although the presence of a high-grade tumour is undoubtedly an important risk factor, it is only one of the characteristics of "high-risk" cSCC, together with recurrent disease, perineural invasion, and incomplete excision [28, 29].

Our findings underscore the importance of teaching young people early in their school years about the risks of developing skin cancer, particularly in farming populations in which many individuals may be less likely to continue their education beyond primary school. Available data (mostly from Australia) clearly demonstrate that early and wide-ranging educational programs can help to slow the rapidly increasing incidence of skin cancer [30, 31]. Although students need greater education about skin cancer risks, workers in at-risk occupations should also be targeted because prevention - especially in those likely to develop high-grade tumours - is a more effective intervention than treatment.

\section{Strengths and limitations}

Our study has several limitations. First, we were unable to perform a multivariate analysis because the sample size of patients with G1 and G3 tumours was insufficient. Another limitation is that many patients reported changing jobs during the course of their working lives and thus it was difficult to clearly assign them to a specific category. However, to overcome this limitation, we divided patients into 3 larger subgroups (outdoor, mixed and indoor work) after asking detailed questions about their work history. Finally, direct comparisons with other countries are difficult due to differences in the educational systems: in Poland, most students graduate from 
primary school at the age of 15 , whereas primary school graduates may be younger in other countries.

\section{Conclusions}

This is the first study to report differences in tumour differentiation between outdoor and indoor workers. Our findings confirm that people with outdoor occupations are at a greater risk of developing higher malignancy tumours. This finding may provide additional support for the inclusion of CSCC in international lists of occupational diseases. The results of this study underscore the importance of prevention programs in at-risk populations and educational programs during primary school.

\section{Acknowledgments}

The authors wish to thank Bradley Londres for his assistance in editing and improving this manuscript.

\section{Conflict of interest}

The authors declare no conflict of interest.

\section{References}

1. Karia PS, Han J, Schmults CD. Cutaneous squamous cell carcinoma: estimated incidence of disease, nodal metastasis, and deaths from disease in the United States, 2012. J Am Acad Dermatol 2013; 68: 957-66.

2. Kyrgidis A, Tzellos TG, Vahtsevanos K, Triaridis S. New concepts for basal cell carcinoma. Demographic, clinical, histological risk factors, and biomarkers. A systematic review of evidence regarding risk for tumor development, susceptibility for second primary and recurrence. J Surg Res 2010; 159: 545-56.

3. Baker NJ, Webb AAC, Macpherson D. Surgical management of cutaneous squamous cell carcinoma of the headand neck. Br J Oral Maxillofac Surg 2001; 39: 87-90.

4. Szewczyk M, Pazdrowski J, Golusiński P, et al. Analysis of selected risk factors for nodal metastases in head and neck cutaneous squamous cell carcinoma. Eur Arch Otorhinolaryngol 2015; 272: 3007-12.

5. Martinez JC, Cook JL. High-risk cutaneous squamous cell carcinoma without palpable lymphadenopathy: is there a therapeutic role for elective neck dissection? Dermatol Surg 2007; 33: 410-20.

6. Kütting B, Drexler H. UV-induced skin cancer at workplace and evidence-based prevention. Int Arch Occup. Environ Health 2010; 83: 843-54.

7. Agar NS, Halliday GM, Barnetson RS, et al. The basal layer in human squamous tumors harbors more UVA than UVB fingerprint mutations: a role for UVA in human skin carcinogenesis. Proc Natl Acad Sci USA 2004; 101: 4954-9.

8. Godar DE. UV doses worldwide. Photochem Photobiol 2005; 81: 736-49.

9. Schmitt J, Seidler A, Diepgen TL, Bauer A. Occupational ultraviolet light exposure increases the risk for the development of cutaneous squamous cell carcinoma: a systematic review and meta-analysis: occupational UV exposure and cutaneous SCC. Br J Dermatol 2011; 164: 291-307.

10. Diepgen TL, Brandenburg S, Aberer W, et al. Skin cancer induced by natural UV-radiation as an occupational disease
- requirements for its notification and recognition: occupational skin cancer and natural UV radiation. JDDG J Dtsch Dermatol Ges 2014; 12: 1102-6.

11. Marehbian J, Colt JS, Baris D, et al. Occupation and keratinocyte cancer risk: a population-based case-control study. Cancer Causes Control 2007; 18: 895-908.

12. Diepgen TL. Occupational skin diseases. JDDG J Dtsch Dermatol Ges 2012; 10: 297-315.

13. Brash DE. Roles of the transcription factor p53 in keratinocyte carcinomas. Br J Dermatol 2006; 154: 8-10.

14. McGuire JF, Ge NN, Dyson S. Nonmelanoma skin cancer of the head and neck I: histopathology and clinical behavior. Am J Otolaryngol 2009; 30: 121-33.

15. Czarnecki D, Meehan CJ, Bruce F, Culjak G. The majority of cutaneous squamous cell carcinomas arise in actinic keratoses. J Cutan Med Surg 2002; 6: 207-9.

16. Rowe DE, Carroll RJ, Day CL. Prognostic factors for local recurrence, metastasis, and survival rates in squamous cell carcinoma of the skin, ear, and lip: implications for treatment modality selection. J Am Acad Dermatol 1992; 26: 976-90.

17. Oberyszyn TM. Non-melanoma skin cancer: importance of gender, immunosuppressive status and vitamin D. Cancer Lett 2008; 261: 127-36.

18. Ch'ng S, Clark JR, Brunner M, et al. Relevance of the primary lesion in the prognosis of metastatic cutaneous squamous cell carcinoma. Head Neck 2013; 35: 190-4.

19. Ebrahimi A, Clark JR, Ahmadi N, et al. Prognostic significance of disease-free interval in head and neck cutaneous squamous cell carcinoma with nodal metastases. Head Neck 2013; 35: 1138-43.

20. Godar DE. UV doses worldwide. Photochem Photobiol 2005; 81: 736-49.

21. Popp S, Waltering S, Herbst C, et al. UV-B-type mutations and chromosomal imbalances indicate common pathways for the development of Merkel and skin squamous cell carcinomas. Int J Cancer 2002; 99: 352-60.

22. Ultraviolet B Irradiation Induces Expansion of Intraepithelial Tumor Cells in a Tissue Model of Early Cancer Progression.

23. Reeder Al, Gray A, McCool J P. Occupational sun protection: workplace culture, equipment provision and outdoor workers' characteristics. J Occup Health 2013; 55: 84-97.

24. Nahar VK, Ford MA, Boyas JF, et al. Skin cancer preventative behaviors in state park workers: a pilot study. Environ Health Prev Med 2014; 19: 467-74.

25. Buster KJ, You Z, Fouad M, Elmets C. Skin cancer risk perceptions: a comparison across ethnicity, age, education, gender, and income. J Am Acad Dermatol 2012; 66: 771-9.

26. Ewertz M, Christensen K, Engholm G, et al. Trends in cancer in the elderly population in Denmark, 1980-2012. Acta Oncol 2016; 55 Suppl 1: 1-6.

27. Pedersen JK, Engholm G, Skytthe A, Christensen K; the Academy of Geriatric Cancer Research (AgeCare). Cancer and aging: epidemiology and methodological challenges. Acta Oncol 2016; 55: 7-12.

28. Veness MJ, Palme CE, Morgan GJ. High-risk cutaneous squamous cell carcinoma of the head and neck: results from 266 treated patients with metastatic lymph node disease. Cancer 2006; 106: 2389-96.

29. Gurudutt VV, Genden EM. Cutaneous squamous cell carcinoma of the head and neck. J Skin Cancer 2011; 2011: 1-10.

30. Staples M. Non-melanoma skin cancer in Australia: the 2002 national survey and trends since 1985. Med J Aust 2006; 184: 6-10.

31. Tan S, Sinclair C, Foley P. Running behind a tourist: leisurerelated skin cancer prophylaxis: leisure-related skin cancer prophylaxis. Br J Dermatol 2012; 167: 70-5. 